\section{Rapid, High-Yield Method for the Bulk Purification of Fibronectin from Human Plasma}

BioTechniques 28:636-638 (April 2000)

Fibronectin is an abundant, high molecular-weight, extracellular glycoprotein that exists in a soluble form in body fluids and in an insoluble form in the extracellular matrix $(3,4)$. Fibronectin plays a major role in many important physiological processes, such as embryogenesis, wound healing, hemostasis and thrombosis. It is a highly affinity-adhesive protein that binds to numerous matrix macromolecules, including collagen or gelatin, fibrin (ogen), heparin and other glycosaminoglycans, as well as cell surface receptors. Fibronectin has been used extensively in tissue culture as a reagent that effectively adheres cells to various substrata. However, fibronectin is a relatively costly reagent, and it is difficult for many laboratories to prepare it themselves. A low-cost and high-yield method for the isolation of pure fibronectin would significantly reduce the cost of performing many types of tissue culture. Here, we describe a procedure for producing chromatographically pure fibronectin using an inexpensive and simple process based on gelatin bead affinity chromatography.

Gelatin beads were prepared using a modification of the procedure described by Atkanov et al. (1). Sunflower oil $(300 \mathrm{~mL})$ was preheated to $50^{\circ} \mathrm{C}$ in a pre-siliconized, flat-bottomed glass flask with a $7 \mathrm{~cm}$ stir bar. This mixture was spun at $200 \mathrm{rpm}$. Then, 70 $\mu \mathrm{L}$ of Triton ${ }^{\circledR} \mathrm{X}-114$ was added to the oil, and the sample was stirred for 5 min. An aqueous phase containing $12 \mathrm{~g}$ of porcine skin gelatin (Sigma, St. Louis, MO, USA) dissolved in $60 \mathrm{~mL}$ of deionized water (also preheated to $50^{\circ} \mathrm{C}$ ) was added to the oil. The rotation speed was increased to approximately $500 \mathrm{rpm}$, and the mixture was stirred for $30 \mathrm{~min}$.

Alternatively, the oil and gelatin mixture was placed in a tabletop blender and the mixture blended on the lowest setting for $5 \mathrm{~min}$. This oil and gelatin mixture was then cooled immediately to $18^{\circ} \mathrm{C}$ by immersion in an ice/water bath. The beads were separated from the oil emulsion by sedimentation as follows: $500 \mathrm{~mL}$ PBS (pH 7.3), containing 0.2\% Triton X-100 was added slowly to the cooled emulsion and stirred for another $10 \mathrm{~min}$. The gelatin beads were allowed to settle out of the emulsified oil phase for at least $1 \mathrm{~h}$. Often, this is a convenient overnight stopping point for the procedure. The remaining supernatant oil was then removed, and the beads were washed $3 \times$ with cold $\left(4^{\circ} \mathrm{C}\right)$ deionized water. The sedimentation time of the beads was 10 min between washes. The beads were then stabilized by glutaraldehyde fixation. The beads were suspended in $500 \mathrm{~mL}$ of PBS containing $2 \mathrm{~mL}$ electron microscopy-grade glutaraldehyde (25\%, Sigma) and the solution stirred for an additional hour at room temperature. The beads were then washed $3 \times$ with deionized water.

The beads prepared in this manner were used for conventional fibronectingelatin affinity chromatography as previously described (1). The following procedures were performed at room temperature. Blood from normal nonmedicated adults $(50 \mathrm{~mL})$ was collected by venipuncture using heparin as an anticoagulant. The blood was centri- fuged at $1000 \times g$ in a Sorvall ${ }^{\circledR}-2 B$ centrifuge (Dupont, Wilmington, DE, USA) for $30 \mathrm{~min}$ to separate plasma from packed red cells. The plasma was supplemented with PMSF in ethanol to a final concentration of $44 \mu \mathrm{g}$ per every $25 \mathrm{~mL}$ of plasma ( $44 \mu \mathrm{L}$ of a $1 \mathrm{mg} / \mathrm{mL}$ solution in absolute ethanol). Plasma plus PMSF $(25 \mathrm{~mL})$ was added to 25 $\mathrm{mL}$ of gelatin beads and rocked overnight $(12 \mathrm{~h})$ at room temperature. Twenty-five milliliters of beads mixed with $25 \mathrm{~mL}$ of treated plasma were applied to a column made of a $50 \mathrm{~mL}$ pipet plugged with $1 \mathrm{~cm}$ of glass wool and $1 \mathrm{~cm}$ of washed sand. The column was perfused with approximately 10 column volumes of PBS (250-300 mL) to wash off contaminating plasma proteins, mainly albumin.

After the column had been washed thoroughly, the fibronectin bound to the beads was eluted with $4 \mathrm{M}$ urea, 50 $\mathrm{mM}$ Tris ( $\mathrm{pH}$ 7.5). We collected fifty 5 $\mathrm{mL}$ fractions on a fraction collector. The protein content in each sample was determined by sampling $10 \mu \mathrm{L}$ from each tube to determine the peak protein fractions from the column (Figure 1). The protein-rich fractions were pooled (approximately $50 \mathrm{~mL}$ ) and immediately dialyzed against 2 L of PBS to remove the urea. Dialysis was carried out twice to reduce urea to negligible levels. Spectrapor cellulose dialysis mem-

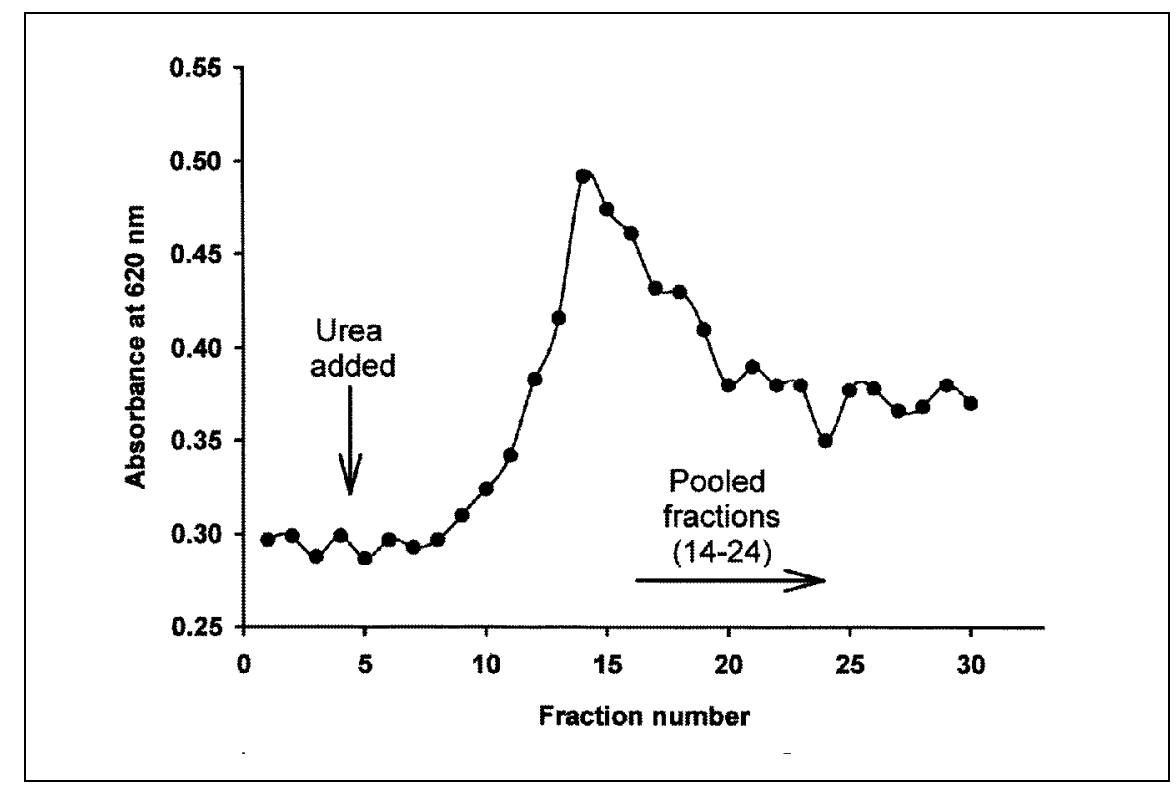

Figure 1. Elution profile of fibronectin from gelatin matrix column. Protein-containing fractions appear around fraction 10. Fractions $14-24($ total $=50 \mathrm{~mL})$ were pooled for dialysis. 
brane (12-14 kDa cutoff) was used (Spectrum, Los Angeles, CA, USA). Fibronectin was then $0.2 \mu \mathrm{m}$ filter-sterilized and adjusted to $10 \mu \mathrm{g} / \mathrm{mL}$ for use in adhering cells to tissue culture plastic. We analyzed the fibronectin prepared in this manner by gel electrophoresis (Figure 2). This fibronectin is greater than $99 \%$ pure, as determined by scanning densitometry of the approximately $200 \mathrm{kDa}$ band and by Western analysis with anti-human fibronectin antibody (Sigma) (2). The amount of fibronectin recovered from $25 \mathrm{~mL}$ of plasma was determined to be $60 \mu \mathrm{g} / \mathrm{mL}$. The cost of the fibronectin

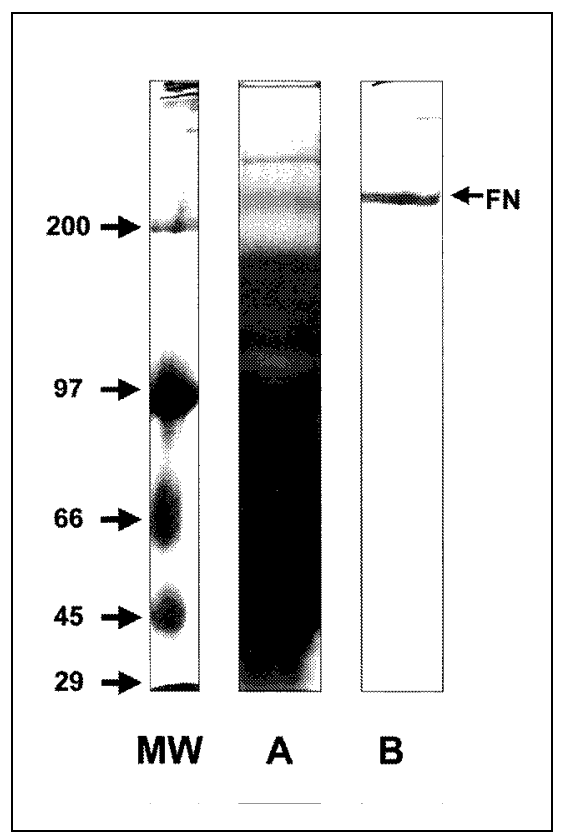

Figure 2. Chromatographic purity of $\mathrm{fi}$ bronectin compared to whole plasma. MW = molecular weight standard. Lane A $=20 \mu \mathrm{g} \mathrm{sam}$ ple of whole plasma. Lane $\mathrm{B}=20 \mu \mathrm{g}$ of fibronectin.

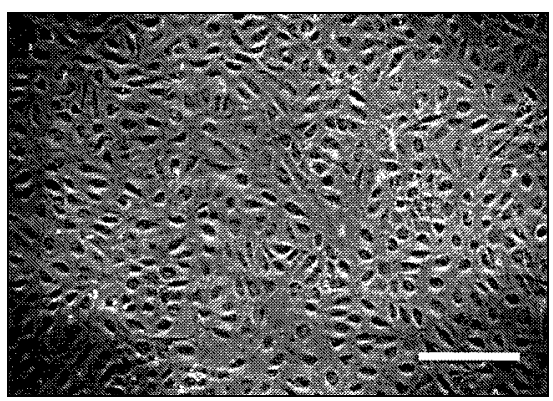

Figure 3. Human umbilical vein endothelial cells cultured on gelatin bead-purified fibronectin. $\mathrm{Bar}=100 \mu \mathrm{m}$. produced in this manner was less than $\$ 5.00$ per preparation (not withstanding the cost of blood donors). This preparation yielded a total of $900 \mu \mathrm{g}$ of fibronectin. Assuming that the concentration of fibronectin in human plasma is $165 \mu \mathrm{g} / \mathrm{mL}$, this procedure yields $37 \%$ of the total possible fibronectin (5). While not addressed here, it is likely that this matrix would also bind cellderived fibronectins in addition to plasma fibronectins.

The quality of the fibronectin produced in this manner was evaluated by seeding human umbilical vein endothelial cells onto this matrix and allowing cells to attach to it as a support matrix (Figure 3). We found that gelatin beadisolated fibronectin supported a high level of endothelial cell adhesion, which was indistinguishable from commercially prepared fibronectin. A hemagglutinating fraction has been reported to co-elute with fibronectin when urea is used as an eluant (5). Therefore, elution of fibronectin could also be performed using $50 \mu \mathrm{M}$ sodium citrate, $0.1 \mathrm{M} \mathrm{NaCl}(\mathrm{pH} 5.5)$ to remove this activity and prevent the potential denaturation of fibronectin by urea (5). For laboratories that use a large amount of fibronectin, this procedure could represent a savings of hundreds to thousands of dollars in lab supplies annually. Similarly, labs that purchase gelatin Sepharose ${ }^{\circledR}$ might successfully use these beads to isolate different cell-derived fibronectins. Once produced and stored at $4^{\circ} \mathrm{C}$, the beads give a similar performance after six months of storage; therefore, bulk preparation of these gelatin beads could be carried out well in advance for purification of fibronectin when needed.

\section{REFERENCES}

1.Altankov, G., I. Brodvarova and I. Rashkov. 1991. Synthesis of protein-coated gelatin microspheres and their use as microcarriers for cell culture. J. Biomater. Sci. Polymer Edn. 2:81-89.

2.Blake, M.S., K.H. Johnston, G.J. RussellJones and E.C. Gotschlich. 1984. A rapid, sensitive method for detection of alkaline phosphatase-conjugated anti-antibody on Western blots. Anal. Biochem. 136:175-179.

3.Hynes, R.O. 1990. Fibronectins. SpringerVerlag Publishers, New York.

4.Mosher, D.R. 1982. Fibronectin-relevance to hemostasis and thrombosis. In Hemostasis and Thrombosis: Basic Principles and Clinical Practice. p. 174-184. J.P. Lippincott, R.W. Colman, J. Hirsh, V.J. Marder and E.W. Salzman (Eds.), J.P. Lippincott and Co., Philadelphia.

5.Smith, R.L. and S.A. Griffin. 1985. Separation of plasma fibronectin from associated hemagglutinating activity by elution from gelatin-agarose at $\mathrm{pH}$ 5.5. Thrombosis Res. 37:91-101.

Address correspondence to Dr. J. Steven Alexander, Louisiana State University Medical Center, Molecular and Cellular Physiology, 1501 Kings Highway, Shreveport, LA 71130,USA. Internet: jalexa@lsumc.edu

Received 17 September 1999; accepted 27 December 1999.

M. Harper, T.L. Thompson, Y.-N. Zhu, R.L. Smith, D. Carden, L. Coe, B. Alexander and J.S. Alexander Louisiana State University Health Sciences Center Shreveport, LA, USA 